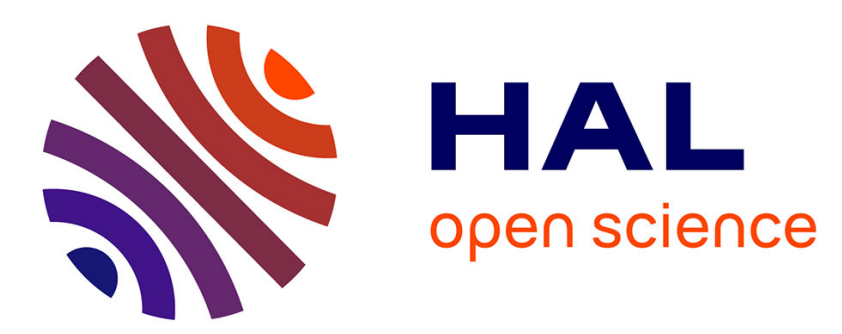

\title{
Functional fluxolipidomics of polyunsaturated fatty acids and oxygenated metabolites in the blood vessel compartment
}

Michel Lagarde, Catherine Calzada, Charlotte Jouvène, Nathalie

Bernoud-Hubac, Marion Létisse, Michel Guichardant, Evelyne Véricel

\section{To cite this version:}

Michel Lagarde, Catherine Calzada, Charlotte Jouvène, Nathalie Bernoud-Hubac, Marion Létisse, et al.. Functional fluxolipidomics of polyunsaturated fatty acids and oxygenated metabolites in the blood vessel compartment. Progress in Lipid Research, 2015, 60, pp.41-49. 10.1016/j.plipres.2015.10.001 . inserm-01228992

\section{HAL Id: inserm-01228992 https://www.hal.inserm.fr/inserm-01228992}

Submitted on 16 Nov 2015

HAL is a multi-disciplinary open access archive for the deposit and dissemination of scientific research documents, whether they are published or not. The documents may come from teaching and research institutions in France or abroad, or from public or private research centers.
L'archive ouverte pluridisciplinaire HAL, est destinée au dépôt et à la diffusion de documents scientifiques de niveau recherche, publiés ou non, émanant des établissements d'enseignement et de recherche français ou étrangers, des laboratoires publics ou privés. 
Review

\title{
Functional fluxolipidomics of polyunsaturated fatty acids and oxygenated metabolites in the blood vessel compartment
}

\author{
M. Lagarde , C. Calzada, C. Jouvène, N. Bernoud-Hubac, M. Létisse, M. Guichardant, \\ E. Véricel \\ Université de Lyon, Inserm UMR 1060, Inra UMR 1397, IMBL, INSA-Lyon, Villeurbanne, \\ France
}

Corresponding author: michel.lagarde@insa-lyon.fr

\begin{abstract}
Synthesis of bioactive oxygenated metabolites of polyunsaturated fatty acids and their degradation or transformation products are made through multiple enzyme processes. The kinetics of the enzymes responsible for the different steps are known to be quite diverse, although not precisely determined. The location of the metabolites biosynthesis is diverse as well. Also, the biological effects of the primary and secondary products, and their biological life span are often completely different. Consequently, phenotypes of cells in response to these bioactive lipid mediators must then depend on their concentrations at a given time. This demands a fluxolipidomics approach that can be defined as a mediator lipidomics, with all measurements done as a function of time and biological compartments. This review points out what is known, even qualitatively, in the blood vascular compartment for arachidonic acid metabolites and number of other metabolites from polyunsaturated fatty acids of nutritional value. The functional consequences are especially taken into consideration.
\end{abstract}

Abbreviations: AdA, adrenic acid; ALA, alpha-linolenic acid; ArA, arachidonic acid; COX, cyclooxygenase; Cyp, cytochrome $\mathrm{P}_{450}$; DAG, diacylglycerol;DHA, docosahexaenoic acid; DGLA, dihomo-gammalinolenic acid; EET, epoxyeicosatrienoate; EPA, eicosapentaenoic acid; EPE, eicosapentaenoate;GPx, glutathione peroxidase; HDoHE, hydroxyl-docosahexaenoate;H(p)ETE, hydro(pero)xyleicosatetraenoate; HETrE, hydroxy-eicosatrienoate;HODE, hydroxyloctadecadienoate; HOTE, hydroxyl-octadecatrienoate;LA, linoleic acid; LOX, lipoxygenase; LT, leukotriene; PMN, polymorphonuclear neutrophil; PG, prostaglandin; PLA, phospholipase A; PLC, phospholipase C;Tx, thromboxane

\section{Introduction}


Polyunsaturated fatty acids (PUFA) are mainly esterified at the $s n-2$ position in glycerophospholipids of animal cell membranes, and may be released by phospholipases, especially phospholipases $A_{2}$ in response to cell activation. Some of these PUFA may be then quickly oxygenated by cell oxygenases to provide very potent lipid mediators that could lose or change their biological activity following specific metabolic pathways. The kinetics of PUFA release will depend on the phospholipases involved, and the metabolic fate of the resulting non-esterified PUFA will undergo concurrent oxygenation at different rates and reacylation, with preferred routes according to the nature of the PUFA. Similarly, the degradation pathways depend on the different oxygenated products, with even generation of new active mediators instead of inactive products. Measuring the largest possible number of metabolites as a function of time, in an attempt to determine fluxes for each of them, will allow better approaching the phenotype of a biological system, with a global view if the measurements are made in different biological compartments. This lipidomics approach, associated with fluxes determination, justifies the name of fluxolipidomics, as in other approaches lipidomics may be focused on a specific class of lipids giving the names of mediator lipidomics and structure lipidomics. Special attention will be paid in this review to those lipid mediators produced in blood platelets, endothelial cells and leukocytes that play important roles in the athero-thrombosis regulation, and which are close to cell compartments.

This review will focus on these aspects, with qualitative considerations for the enzyme kinetics that are not known yet in detail.

\section{PUFA relevant for cell functions}

The most abundant PUFA in animal cells are presented in Fig. 1. The major PUFA is arachidonic acid (ArA or 20:4n-6), except in the brain and retina where the major one is docosahexaenoic acid (DHA or 22:6n-3) [1]. However, the PUFA content of most tissues changes in response to environment, notably the remodeling of phospholipid composition by nutrition [2]. The brain may be an exception because of the blood-brain barrier that exerts selective crossing of PUFA, which likely explains its high enrichment in DHA [3]. 

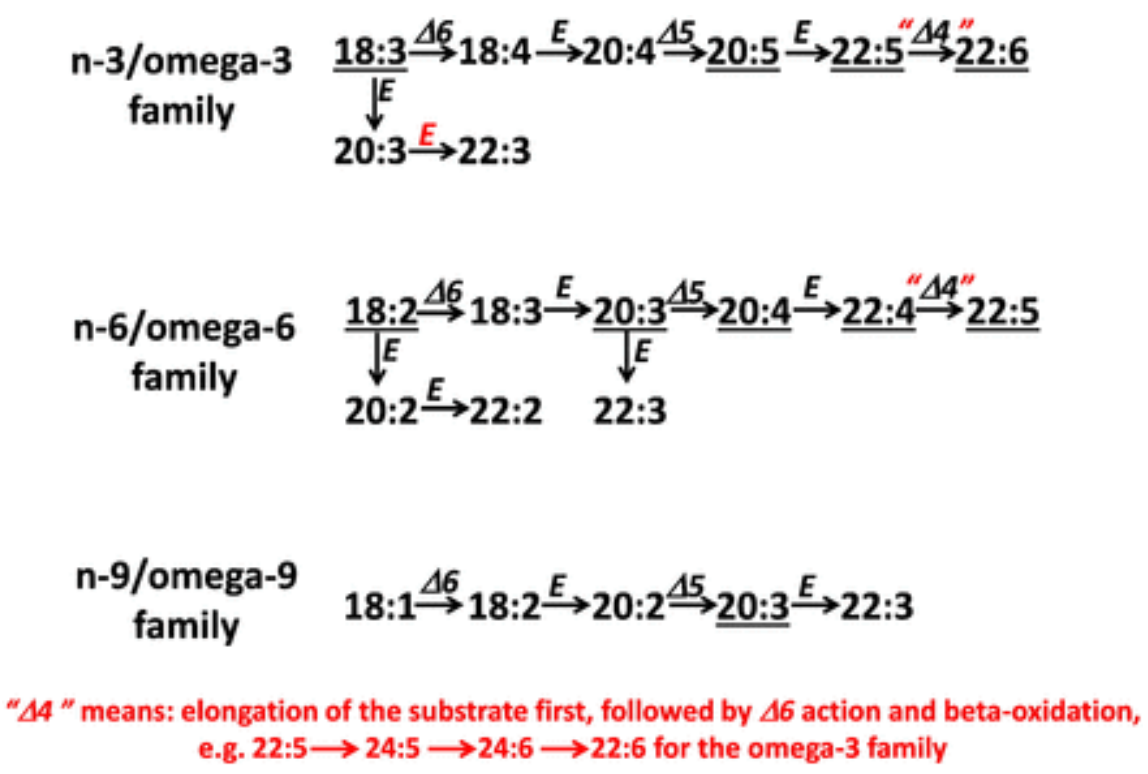

Fig. 1 Biogenesis of the most frequent polyunsaturated fatty acids (PUFA). These PUFA belong to the three n-3/omega-3, n-6/omega- 6 and n-9/omega-9 families. $E$ indicates an elongase, and $\Delta$ a desaturase, followed by the carbon number of the new double bond issued from the desaturation. However, $\Delta 4$ has quotation marks because it means $\Delta 4$ desaturation instead of $\Delta 4$ desaturase in one step. It must be taken as a more complex step than the other desaturation (e.g. $\Delta 5$ and $\Delta 6$ ). Indeed $\Delta 4$ desaturation includes first a further elongation, followed by $\Delta 6$ action, and finally beta-oxidation [105].PUFA undergoing oxygenation metabolism and addressed in this review are underlined. They are: 18:3n-3: alpha-linolenic acid (ALA, 9,12,15-octadecatrienoic acid); 20:5n-3: eicosapentaenoic acid (EPA, 5,8,11,14,17-eicosapentaenoic acid); 22:5n-3: docosapentaenoic acid (DPAn-3, 7,10,13,16,19-docosapentaenoic acid); 22:6n-3: docosahexaenoic acid (DHA, 4,7,10,13,16,19-docosahexaenoic acid); 18:2n-6: linoleic acid (LA, 9,12-octadecadienoic acid); 20:3n-6: dihomo-gamma-linolenic acid (DGLA, 8,11,14-eicosatrienoic acid); 20:4n-6: arachidonic acid (ArA, 5,8,11,14-eicosatetraenoic acid); 22:4n-6: adrenic acid (AdA, 7,10,13,16-docosatetraenoic acid); 22:5n-6: docosapentaenoic acid (DPAn-6, 4,7,10,13,16docosapentaenoic acid); 20:3n-9: Mead acid (5,8,11-eicosatrienoic acid).

In addition to ArA, the other PUFA of interest within the n-6/omega- 6 family are linoleic acid (LA or 18:2n-6), the most abundant PUFA in plant oils, dihomo-gammalinolenic acid (DGLA or 20:3n-6), the immediate precursor of ArA, and docosatetraenoic/adrenic acid (AdA or 22:4n-6), the elongation product of ArA. Within the n3/omega-3 family fatty acids, the essential precursor alpha-linolenic acid (ALA or 18:3n-3), found in some plant oils, and eicosapentaenoic (EPA or 20:5n-3) as well as docosapentaenoic (DPA or 22:5n-3) acids are the main PUFA of marine origin with DHA. They are the major n3 PUFA of biological interest (Fig. 1). As shown in this figure, other PUFA intermediates 
belong to both families, but their oxygenation metabolism and the biological action of their metabolites have not been investigated in detail. They will not be discussed in the frame of this review.

\section{Arachidonic acid as a reference PUFA}

The main classes of oxygenated PUFA, such as prostanoids, leukotrienes and other oxygenase products, have arachidonic acid (ArA) as the reference precursor [4]. Fig. 2 shows as a general scheme for the main active metabolites and their stable degradation products, all relevant to the blood and vascular cells compartment. Also, ArA is a major PUFA of the peripheral tissues in mammals, including the blood vessel compartment, where its conversion into oxygenated products is of relevance for cell function. Fig. 3 points out some biological functions of relevant primary and secondary metabolites with a special emphasis to antagonistic and synergistic functions. 
A)

N-6 PUFA

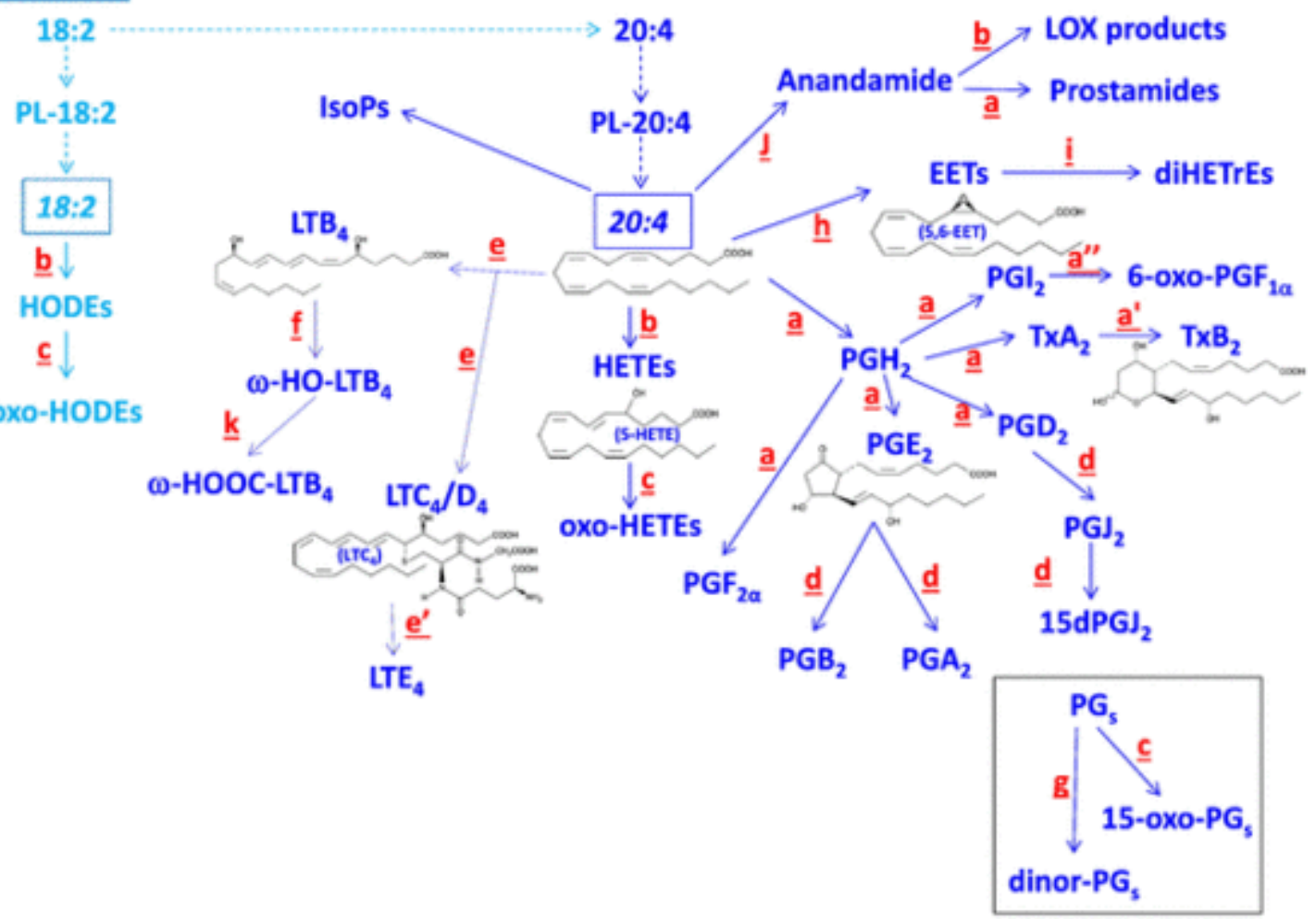

B)

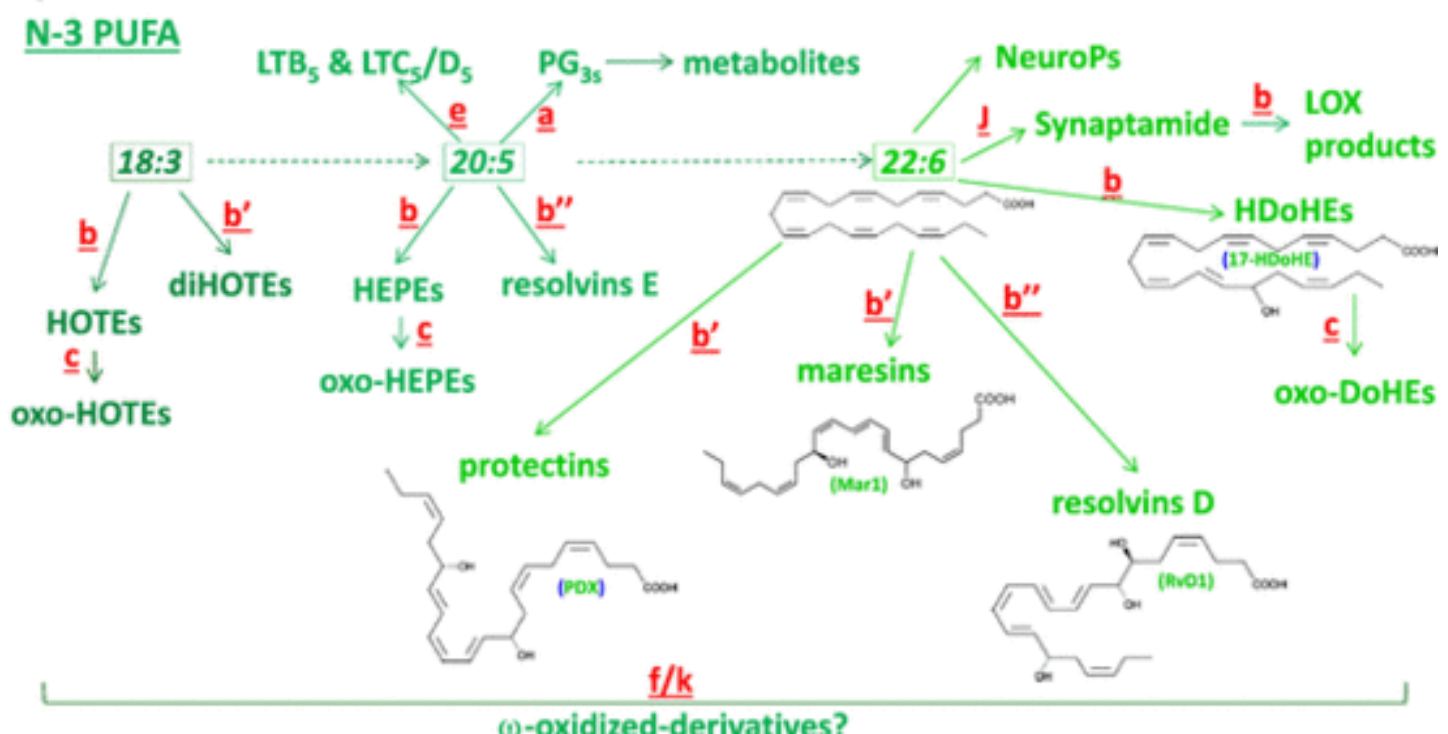

Fig. 2 Main metabolic pathway originating from some of the major PUFA presented in Fig1.The different colors (light and regular blue for 18:2n-6 and 20:4n-6 \& dark (Fig. 2A), regular and light green for 18:3n-3, 20:5n-3 and 22:6n-3 (Fig. 2B), respectively) relate to the different pathways and precursor PUFA.The metabolism of 20:5n-3/EPA is simplified as it is similar to that of 20:4n-6/ArA.Although anandamide and synaptamide are not oxygenated products, but are ethanolamide derivatives of ArA and DHA, respectively, they are mentioned as possible substrates for specific oxygenation, providing LOX products and prostamides. Also, they must be taken into account for the completion of ArA and DHA metabolism at a 
rate that includes their transfer to the ethanolamine moiety of $\mathrm{PE}$ followed by a specific phospholipase D cleavage.PL: phospholipids; PG: prostaglandin; Tx: thromboxane; LT: leukotriene; HETE: hydroxy-eicosatetraenoate; HEPE: hydroxy-eicosapentaenoate; HODE: hydroxy-octadecadienoate; HOTE: hydroxy-octadecatrienoate; HDoHE: hydroxydocosahexaenoate; EET: epoxy-eicosatrienoate. Some 2D structures are shown as representative of several molecular categories, namely $\mathrm{PGE}_{2}$ and $\mathrm{TxB}_{2}$ for cyclooxygenase, $\mathrm{LTB}_{4}, \mathrm{LTC}_{4}$ and 5-HETE for 5-lipoxygenase, and 5,6-EET for cytochrome $\mathrm{P}_{450}$ epoxygenase products from arachidonic acid. Also shown are protectin DX (PDX), resolvin D1 (RvD1) and 17-HDoHE for 15-lipoxygenase, and maresin 1 (Mar1) for 12-lipoxygease products from docosahexaenoic acid.The small letters next to the arrows indicate the enzymes or nonenzyme modifications (e.g. dehydration, hydrolysis) with different letters indicating different kinetics: $\underline{a}:$ Cyclooxygenases \& PGH isomerase; $\underline{a^{\prime}} \& \underline{a^{\prime \prime}}$ : Hydrolysis of thromboxane A \& prostacyclin $\quad\left(\mathrm{PGI}_{2}\right) ; \underline{\mathrm{b}}: \quad$ Lipoxygenases; $\underline{\mathrm{b}}^{\prime} \& \underline{\mathrm{b}^{\prime \prime}}$ : Double $\& \quad$ triple lipoxygenation/hydroxylation; $\underline{c}:$ Hydroxyl-dehydrogenases; $\underline{\mathrm{d}}$ : Dehydration; $\underline{\mathrm{e}}$ : Leukotriene synthases (LTA synthase + LTB \& LTC/D synthases); $\underline{e}^{\prime}:$ Dipeptidase (inactivation of LTD into LTE); $\underline{\mathrm{f}}$ : Omega hydroxylases; g: Beta-oxidation; $\underline{\mathrm{h}}$ : Epoxygenases; $\underline{\mathrm{i}}$ : Epoxide hydrolases; $\underline{\mathrm{J}}$ : Acyl-ethanolamide synthesis; $\underline{\mathrm{k}}$ : Double hydroxyl-dehydrogenase. The possible omega-oxidation of non-cyclized oxygenated products is expected. This is suggested with a question mark for lipoxygenase products of n-3 PUFA with $\underline{\mathrm{f} / \mathrm{k}}$ for the kinetics as it has been properly described in the omega-oxidation of $\mathrm{LTB}_{4}$.No letters are associated with the formation of isoprostanes (IsoPs) and neuroprostanes (NeuroPs), oxygenated products of ArA and DHA, respectively, because they are non-enzymatically produced by reactive oxygen species.

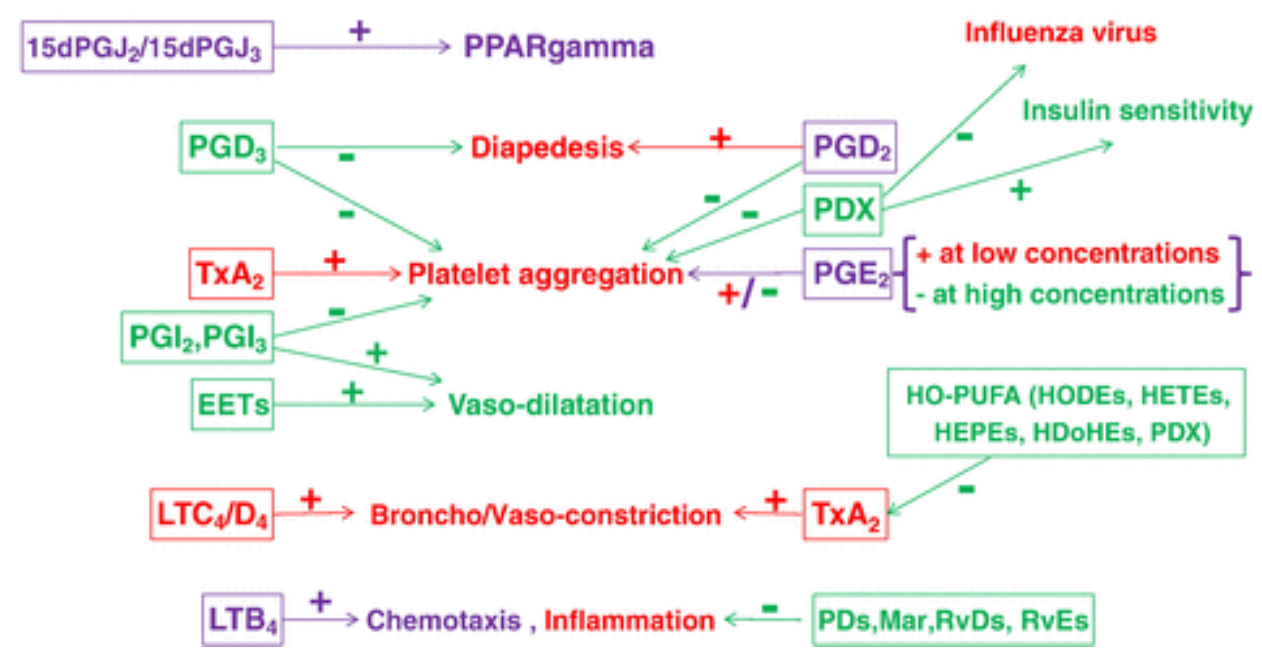

Fig. 3 Some specific effects of primary and secondary oxygenated metabolites of PUFA.The examples given point out antagonistic and synergistic effects. The green and red colors mean beneficial and deleterious effects, respectively. The purple color means bimodal effects in 
function of concentration of the agonist, and/or function of the initial or final target. +and mean positive and negative actions, respectively.

First, ArA must be released from membrane phospholipids in response to cell activation by extracellular messengers. The main phospholipase involved is the cytosolic phospholipase $\mathrm{A}_{2}\left(\mathrm{cPLA}_{2}\right)$ which requires micromolar concentrations of cytosolic calcium ions [5]. This concentration can be reached either by calcium entry from the extracellular space or by release from endoplasmic reticulum [6]. In the latter case, inositol trisphosphate $\left(\mathrm{IP}_{3}\right)$ may be the triggering agent, which establishes a link between the cleavage of phosphatidylinositol-4,5-bisphosphate $\left(\mathrm{PIP}_{2}\right)$ by phospholipase $\mathrm{C}$ (PLC), the primary event, and the activation of $\mathrm{cPLA}_{2}$. The other cleavage product is diacylglycerol (DAG), mainly 1palmitoyl,2-arachidonoyl-glycerol, which is generated prior to the activation of $\mathrm{CPLA}_{2}$. Then, the release of ArA from phospholipids (mainly phosphatidyl-choline and -ethanolamine) by cPLA $_{2}$ may parallel that from ArA-containing DAG by DAG lipase [7], although with different kinetics. However, in terms of quantities, ArA released by $\mathrm{cPLA}_{2}$ is likely higher than that from $\mathrm{PIP}_{2}$ through the PLC/DAG lipase cascade.

Once released, ArA will be either oxygenated by cyclooxygenases (COX), lipoxygenases (LOX) and cytochrome $\mathrm{P}_{450}(\mathrm{Cyp})$ monooxygenases, depending on the cell equipment, or re-acylated into membrane phospholipids by re-esterifying the lysophospholipids produced by the primary cleavage [8].

The cyclooxygenation is considered the fastest stage in the ArA oxygenation, with the self-denaturation of the enzyme due to the release within the enzyme of the oxygen radical produced by hydroperoxidase, the second enzymatic function of prostaglandin (PG) $\mathrm{H}$ synthase [9]. In other words, the primary product of $\mathrm{COX}, \mathrm{PGG}_{2}$ is a 15-hydroperoxide converted into its 15-hydroxyl derivative $\mathrm{PGH}_{2}$ by hydroperoxidase that releases oxygen radicals. This occurs within a few minutes with substantial amount of prostanoids already made in less than 1 min. As a matter of fact, fully active quantities of thromboxane $A_{2}\left(T x A_{2}\right)$ are generated within $30 \mathrm{~s}$ in activated blood platelets, resulting from the isomerization of $\mathrm{PGH}_{2}$ by thromboxane synthase [10]. The pro-aggregatory action of $\mathrm{TxA}_{2}$ generated by platelets themselves may be modulated by primary prostaglandins concomitantly issued from $\mathrm{PGH}_{2}$. This is true for $\mathrm{PGE}_{2}$ which potentiates platelet aggregation at low concentrations through lowering cyclic AMP (cAMP) in response to the $\mathrm{PGE}_{2}$ receptor type 3 (EP3) coupled with a Gi-protein. However, platelet aggregation will be inhibited by the rise of cAMP due to both the increased concentrations of $\mathrm{PGE}_{2}$ and $\mathrm{PGD}_{2}[11,12]$ acting through EP2 and DP1, respectively, coupled with Gs-proteins [13]. So, the early stage (less than $1 \mathrm{~min}$ ) of platelet stimulation will favor their aggregation through the $\mathrm{TxA}_{2}$ action, and low concentrations of $\mathrm{PGE}_{2}$. Later stages will promote non-enzymatic degradation of $\mathrm{TxA}_{2}$ (half-life evaluated to 
30s in physiological media) into the inactive and stable $\mathrm{TxB}_{2}$, and the predominance of $\mathrm{PGD}_{2}$ and higher concentrations of $\mathrm{PGE}_{2}$ will inhibit platelet aggregation. Moreover, $\mathrm{PGE}_{2}$ is further chemically dehydrated into inactive $\mathrm{PGA}_{2}$ (acidic conditions) or $\mathrm{PGB}_{2}$ (basic conditions) [14], and $\mathrm{PGD}_{2}$ into $\mathrm{PGJ}_{2}$, a mitogenic metabolite [15], and further into 15-deoxy$\mathrm{PGJ}_{2}$, a peroxisome proliferating-activator receptor (PPAR) gamma ligand [16]. Although $\mathrm{PGJ}_{2}$ and 15-dPGJ ${ }_{2}$ have no defined biological activities in blood platelets, together with other metabolites such as TxB2, $\mathrm{PGE}_{2}, \mathrm{PGD}_{2}, \mathrm{PGA}_{2}, \mathrm{PGB}_{2}, \mathrm{PGJ}_{2}$, and 15- $\mathrm{dPGJ}_{2}$, they form mixtures of metabolites relating to platelet phenotypes at different times. To get an overall picture of ArAcyclooxygenation in activated platelets, the measurement of $\mathrm{PGF}_{2 \alpha}$ (another metabolite of $\mathrm{PGH}_{2}$ produced by a specific reductase) and of the cleavage products of $\mathrm{PGH}_{2}$, namely 12 hydroxy-heptadecatrienoic acid (12-HHT) plus malondialdehyde (MDA), is needed, although both $\mathrm{PGF}_{2 \alpha}$ and $12-\mathrm{HHT}$ are inactive in platelets [17]. It must be added that the primary prostaglandin formation does not only follow the kinetics of $\mathrm{PGH}_{2}$ production, because different PGD, E and F synthases have been described[18, 20], in addition to the spontaneous isomerization of $\mathrm{PGH}_{2}$ into $\mathrm{PGD}_{2}$ and $\mathrm{E}_{2}$ catalyzed by albumin.

In addition to this cyclooxygenation, ArA is substantially oxygenated by 12 lipoxygenase (LOX) for production of 12-hydroperoxy-eicosatetraenoic acid (12-HpETE), that is further reduced to 12-hydroxy-eicosatetraenoic acid (12-HETE) by glutathione peroxidase (GPx)-1 [21]. Those two molecules are also able to modulate platelet aggregation; 12-HpETE is an activator of both the release of ArA through cPLA $\mathrm{A}_{2}$ and its oxygenation into prostanoids by stimulating the cyclooxygenase activity [22]. In contrast, the accumulation of 12-HETE may inhibit the reactivity of $\mathrm{TxA}_{2}$ [23], at the level of its receptor site [24]. The kinetics of 12-LOX is slower than that of COX, but more stable with time, meaning that the early 12 -LOX activity might potentiate the $\mathrm{TxA}_{2}$-dependent aggregation whereas the later 12LOX activity might inhibit it, as do $\mathrm{PGD}_{2}$ and the late $\mathrm{PGE}_{2}$. The measurement of the stable 12-HETE at different times will then complete the picture outlined with prostanoids.

A cellular aspect of the endothelium, is worth to be mentioned relating to platelet aggregation. Indeed, an important oxygenation route of ArA in endothelial cells is its conversion into prostacyclin or $\mathrm{PGI}_{2}$, a potent inhibitor of platelet aggregation through a Gscoupled IP receptor on platelet membranes. The half-life of $\mathrm{PGI}_{2}$ is short (around 2min)

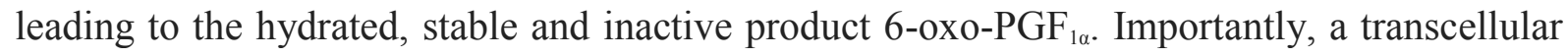
metabolism between endothelial cells and platelets has been demonstrated with some $\mathrm{PGH}_{2}$ of platelet origin being transformed into $\mathrm{PGI}_{2}$ by endothelial prostacyclin synthase [25], with subsequent slowing down of platelet aggregation. Even more complex, the inhibition of platelet aggregation by $\mathrm{PGI}_{2}$-derived endothelial cells may be enhanced by activated lymphocytes that stimulate endothelial $\mathrm{cPLA}_{2}$ [26]. In addition, a substantial part of ArA may 
be converted into 15-HpETE by the endothelial 15-LOX, and 15-HpETE has been reported to be an inhibitor of prostacyclin synthase [27], although it may potentiate endothelial cyclooxygenase due to its requirement for peroxides, like all cyclooxygenases [28]. The relative kinetics of these ArA metabolites are not precisely known, but we may reasonably anticipate that only $15-\mathrm{HpETE}$ is active on the generation of $\mathrm{PGI}_{2}$, with a decreased formation from $\mathrm{PGH}_{2}$ of platelet origin. A time-dependent determination of stable metabolites of ArA from platelets and from endothelium, namely 6-oxo-PGF ${ }_{1 \alpha}$ and 15-HETE (the reduction product of 15 -HpETE), appearsto be the only way to properly approach this endotheliumplatelet antagonism model.

Other blood cell types are functionally important relating to the oxygenation metabolism of ArA. This is the leukocyte compartment, especially polymorphonuclears (PMNs) and eosinophils that have original oxygenated metabolism of ArA. PMNs have been extensively studied for their production of leukotriene (LT) $B_{4}\left(\mathrm{LTB}_{4}\right)$, a potent chemotactic and pro-inflammatory derivative [29]. Its biosynthesis is initiated by 5-LOX which makes first 5-HpETE and second a 5,6-epoxide derivative having a conjugated triene (7E,9E,11Z), called leukotriene $\mathrm{A}_{4}\left(\mathrm{LTA}_{4}\right)$. $\mathrm{LTA}_{4}$ is unstable because of its epoxide next to the conjugated triene. PMNs have an enzyme, called LTA hydrolase or LTB synthase, that specifically adds one molecule of water with the hydroxyl moiety on carbon 12 and the hydrogen making the other hydroxyl at carbon 5 from the opening of the 5,6-epoxide. These additions induce the migration back of the conjugated triene from $7 \mathrm{E}, 9 \mathrm{E}, 11 \mathrm{Z}$ to $6 \mathrm{Z}, 8 \mathrm{E}, 10 \mathrm{E}$. The hydrolysis of $\mathrm{LTA}_{4}$ by LTA hydrolase also is stereospecific with $\mathrm{LTB}_{4}$ being 5S,12R-diHETE $(6 \mathrm{Z}, 8 \mathrm{E}, 10 \mathrm{E}, 14 \mathrm{Z})$ [30]. These structural considerations are crucial for the biological activity of $\mathrm{LTB}_{4}$, because the unstable $\mathrm{LTA}_{4}$ is concurrently hydrolyzed into two isomers, namely 12-epi-

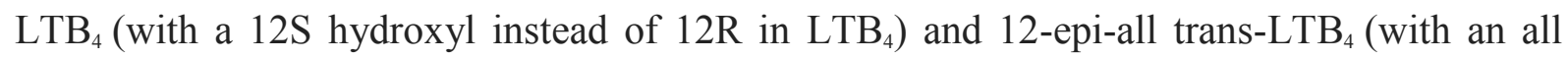
trans conjugated triene: $6 \mathrm{E}, 8 \mathrm{E}, 10 \mathrm{E})$, that are both biologically inactive [31]. However, the simultaneous measurement of $\mathrm{LTB}_{4}$ and its two isomers is needed, as well as that of 5-HETE produced by GPx reduction of a fraction of 5-HpETE before its conversion into LTA 4 . These measurements as a function of time will allow evaluating the pro-inflammatory potential of activated PMNs. Importantly, the metabolism of $\mathrm{LTB}_{4}$ within PMNs also will modulate that pro-inflammatory potential. Indeed, $\mathrm{LTB}_{4}$ undergoes omega oxidation with first a Cyp $\mathrm{P}_{450^{-}}$ dependent hydroxylation of the methyl terminus, providing $20-\mathrm{OH}-\mathrm{LTB}_{4}$, followed by double NAD-dependent oxidation of the primary alcohol into a carboxylic acid, the final product being 20-carboxy- $\mathrm{LTB}_{4}$. These downstream omega oxidations are supposed to be slower than $\mathrm{LTB}_{4}$ generation, and represent a major degradation of $\mathrm{LTB}_{4}$, as $20-\mathrm{OH}-\mathrm{LTB}_{4}$ is partly active and 20-carboxy- $\mathrm{LTB}_{4}$ is inactive. The need for simultaneous measurement of $\mathrm{LTB}_{4}$ and its two successive metabolites is obvious for evaluation of the pro-inflammatory phenotype of the cells. 
A transcellular cooperation between PMNs 5-LOX and platelet 12-LOX has been described in the formation of a geometric and stereo-isomer of $\mathrm{LTB}_{4}$. Its structure is $5 \mathrm{~S}, 12 \mathrm{~S}$ diOH-eicosa-6E,8Z,10E,14Z-tetraenoic acid [32], also known as LTBX. It is much less chemotactic than $\mathrm{LTB}_{4}$, but has later been reported as an inhibitor of platelet aggregation [33], among several other dihydroxylated derivatives of PUFA, called poxytrins, sharing the E,Z,E conjugated triene geometry [34]. Then, LTBX measured as a function of time in whole blood will indicate cooperation and will reflect both, decreased pro-inflammatory potential of PMNs and platelet reactivity to aggregating agents. The intermediates 5- and 12-HETEs may also be dehydrogenated by a NAD-dependent dehydrogenase into 5- and 12-oxo-derivatives, respectively [35]. This metabolism must not be considered as inactivation process because the products have been described with specific biological activities; in particular 5-oxo-ETE promotes eosinophil chemotaxis through specific receptors [36]. This demands measurements of oxo-ETEs for gaining a better picture of the lipoxygenase-dependent biological functions.

Although eosinophils represent a minor population of leukocytes, their capacity to make $\mathrm{LTA}_{4}$ followed by its main conversion into $\mathrm{LTC}_{4}$ by conjugation of $\mathrm{LTA}_{4}$ with reduced glutathione, is of great biological relevance [37]. This biosynthesis is catalyzed by glutathione S-transferase that opens the 5,6-epoxide into 5-OH,6-glutathionyl-7E,9E,11Z,14Zeicosatetraenoic acid $\left(\mathrm{LTC}_{4}\right)$. $\mathrm{LTC}_{4}$ is further converted into $\mathrm{LTD}_{4}$ by removing the gammaglutamyl residue from the glutathionyl moiety, as catalyzed by gamma-Glu transferase. A further modification is the removal of the glycine residue by a dipeptidase, leading to $\mathrm{LTE}_{4}$ keeping the cysteinyl residue at position 6. Because those three LTs have covalently bound one to three amino-acid residues, they are called peptide-LTs. $\mathrm{LTC}_{4}$ and $\mathrm{LTD}_{4}$ have the same biological effects, which are vaso- and broncho-constricting activities. The latter activity is especially important as $\mathrm{LTC}_{4}+\mathrm{LTD}_{4}$ are considered the active principle of the so-called slow reacting substance of anaphylaxis (SRS-A) [38]. In contrast, $\mathrm{LTE}_{4}$ is much less active, and has been assumed as a first degradation product [39]. Again, eosinophil action must be evaluated by time-dependent profiling of the three LTs for a better understanding of their biological roles.

In addition to the specific metabolism of each bioactive oxygenated product reported above, more general pathways are worth to be mentioned. Prostanoids, (except 15- $\mathrm{dPGJ}_{2}$ ) have in common a hydroxyl group at carbon 15 that is targeted by the endothelial 15prostaglandin dehydrogenase (15-PGDH), an NAD-dependent dehydrogenase of this secondary alcohol. 15-PGDH is known to be especially efficient in pulmonary circulation, allowing the formation of 15-oxo-PGs that lose a great part of their biological activities, meaning that most circulating prostanoids will become inactive after a few pulmonary passages [40]. The 15-oxo-PGs derived from this process are further degraded to the 13,14- 
dehydro-15-oxo-PGs by NADPH reduction [41]. The simultaneous measurement of these two types of metabolites contributes to a better understanding of the PG-dependent phenotypes.

Also, prostanoids being all free fatty acids, they undergo one or two classical betaoxidation steps, leading to dinor- and tetranor- derivatives [42]. This latter degradation is likely done on a long term base, because it essentially occurs in liver cell peroxisomes, not in mitochondria [43]. This means that late measurements of beta-oxidation products are also relevant.

Finally, mono-oxygenation of ArA by several Cyp $\mathrm{P}_{450}$ must be considered. ArA may be oxygenated on its methyl terminus to provide 20-HETE, a vasoactive product [44], or to generate epoxides at the expense of each double bond, i.e. 5,6-epoxy-eicosatrienoic acid (EET), 8,9-EET, 11,12-EET and 14,15-EET [45,46]. The latter epoxides are actively hydrolyzed into the corresponding di-hydroxy-eicosatrienoic acids (diHETrE) such as 5,6diHETrE by specific epoxide hydrolases. In contrast to vasoactive 20-HETE and the epoxyderivatives, di-HETrEs appear to be relatively inactive [47]. The measurement of all the Cyp products and hydrolyzed metabolites as a function of time is relevant to evaluate the metabolic fate.

\section{Other prostanoid and dihomo-prostanoid precursors}

Other prostanoid precursors are dihomo-gamma-linolenic acid (DGLA or 20:3n-6), the ArA precursor, and eicosapentaenoic acid (EPA or 20:5n-3), the product of the ArA position isomer $8,11,14,17$-eicosatetraenoic acid (20:4n-3), in the biogenesis of PUFA (Fig. 1).

As for ArA, DGLA and EPA must be first released from membrane phospholipids. According to the specificity of $\mathrm{cPLA}_{2}$ to preferentially release ArA, a double bond proximal to the ester carbon is generally required. EPA should then be released as efficiently as ArA but DGLA would not. Thus, the latter PUFA would mainly be released through the PLC/DAG lipase cascade [7]. This means that the release of DGLA would not be favored in comparison to ArA and EPA. Another important consideration is the level of DGLA and EPA in lipid stores, especially in membrane PLs. According to nutritional data, EPA concentrations in membranes are easily increased in response to marine lipids intake, whereas DGLA is hardly modified even by specific nutritional approaches from gamma-linolenic acid (18:3n-6) as DGLA is easily desaturated to ArA [48].

In terms of oxygenation, DGLA and EPA roughly undergo the same routes as ArA through cyclooxygenases, providing prostanoids of series one and three, respectively. However, thromboxane synthase appears to be highly specific of $\mathrm{PGH}_{2}$, meaning that the enzyme produces much less $\mathrm{TxA}_{1}$ and $\mathrm{TxA}_{3}$ from $\mathrm{PGH}_{1}$ and $\mathrm{PGH}_{3}[49,50]$. Also, $\mathrm{PGI}_{1}$ cannot 
be produced due to the lack of double bond at position 5. In terms of function, the activity of series one prostanoids is not well documented, except for $\mathrm{PGE}_{1}$ that has been primarily described as a potent activator of cell adenylyl cyclase [51]. Regarding series three, $\mathrm{TxA}_{3}$ is virtually not active compared to $\mathrm{TxA}_{2}$ [52]. In contrast $\mathrm{PGI}_{3}$ is as potent as $\mathrm{PGI}_{2}[53]$. $\mathrm{PGD}_{3}$ is as potent as $\mathrm{PGD}_{2}$ to inhibit platelet aggregation [54], but has been reported to be antiinflammatory by inhibiting the leukocyte diapedesis induced by $\mathrm{PGD}_{2}$ [55]. In addition, $\mathrm{PGD}_{3}$ may be converted into $15 \mathrm{dPGJ}_{3}$ that induces the secretion of adiponectin as does 15 $\mathrm{dPGJ}_{2}$ from $\mathrm{PGD}_{2}$, which contributes to the anti-inflammatory activity of EPA [56]. Also, $\mathrm{PGE}_{3}$ appears less pro-inflammatory than $\mathrm{PGE}_{2}$ [57]. Overall $\mathrm{PGD}_{3}$ plus $\mathrm{PGE}_{3}$ express an antiatherothrombogenic profile compared to $\mathrm{PGD}_{2}$ plus $\mathrm{PGE}_{2}$. The production kinetics of series three mediators is assumed to be similar to those of series two. Then we can expect that fluxolipidomics of series three prostanoids should parallel that of series two. The oxygenation of EPA and the main biological actions of the products have been summarized as well in Figs. $2 \mathrm{~B}$ and 3.

The elongation product of ArA, 7,10,13,16-docosatetraenoic acid (22:4n-6), also called adrenic acid (AdA) because of its first discovery in adrenal cells, is a substrate of cyclooxygenases [58,59]. The products are dihomo-prostanoids which seem to be produced similarly to prostanoids from ArA. However, much less is known about the release of AdA from membrane phospholipids, and the biological activity of the products are not known, except for dihomo-PGI ${ }_{2}$ and dihomo-TxA that are believed to be less active than their counterparts from $\mathrm{ArA}[60]$. Also, its structural characteristics enables AdA to be a fairly good substrate of 12- and 15-LOX to produce 14- and 17-oxygenated derivatives, respectively[61]. AdA is easily produced from released ArA by only one elongation step, and measurement of its expected oxygenated products might be important for the balance sheet of ArA oxygenation at each time of cell activation.

As far as the 5-LOX pathway is concerned, DGLA will not be converted into classical leukotrienes because it lacks the double bond at carbon 5, but EPA is a fairly good substrate [62]. Although the routes of EPA to leukotrienes $5\left(\mathrm{LT}_{5 \mathrm{~s}}\right)$, as well as the kinetics of production, are not known to be different from those generating $\mathrm{LT}_{4 \mathrm{~s}}$ from $\mathrm{ArA}$, a fluxolipidomics approach would strengthen the observation that $\mathrm{LTB}_{5}$ is at least ten fold less potent than $\mathrm{LTB}_{4}$ as a pro-inflammatory agent [63]. So the production of $\mathrm{LTB}_{5}$ as a function of time will allow anticipating the global LTB-dependent inflammatory state. This will of course depend on the relative concentrations of the precursors ArA and EPA, in turn depending on the nutritional status of the individual. Regarding the peptide-LTs from EPA, $\mathrm{LTC}_{5}$ and $\mathrm{LTD}_{5}$ have been reported with a biological activity around five times less potent than $\mathrm{LTC}_{4}$ and $\mathrm{LTD}_{4}$ [64]. 
Also, EPA has been described as substrate of Cyp-epoxygenases, normally producing EET from ArA [65]. The biological functions of the EPA products are not well-documented, but they must be taken into considerations in all metabolic fluxes.

Finally, regardless of the ArA pathway, a biologically relevant pathway has been described for EPA. The products are called resolvins (Rv) as they accelerate the resolution of inflammation [66]. At least three resolvins (named $\mathrm{RvE}_{1}, \mathrm{E}_{2}$ and $\mathrm{E}_{3}$ ) are initiated upon acetylation of cyclooxygenase- 2 by aspirin. As the active site of the enzyme is blocked for generation of prostanoids, yet this modified enzyme oxygenates carbon 18 of EPA leading the $\mathrm{R}$ stereo hydroperoxide [67]. Subsequent action of 5-LOX will make both the 5S,12R,18RtriOH-EPE $\left(\mathrm{RvE}_{1}\right)$ and 5S,18R-diOH-EPE or 5S,18R-diHEPE $\left(\mathrm{RvE}_{2}\right)$. An alternative route will convert the 18R-OOH-EPE into 17S,18R-diHEPE $\left(\mathrm{RvE}_{3}\right)$. The kinetics for resolvins $\mathrm{E}$ production are not known, but the fluxolipidomics approach must obviously be applied to this category of metabolites as well.

\section{Lipoxygenation of other PUFA of relevant concentrations in vivo}

Many PUFA of biological interest are not oxygenated into prostanoids through cyclooxygenases, but by lipoxygenases. They have 18, 20 or 22 carbons and at least two double bonds (see Fig. 1).

Linoleic acid (LA, 18:2n-6), the well-known indispensable PUFA as precursor of n-6 or omega-6 PUFA, is not only the precursor of ArA but represents the main PUFA in human blood plasma. It is known as a good substrate of 15-/n-6-LOX, especially in plants [68], to be transformed into 13-OOH-18:2 or 13-hydroperoxy-octadecadienoic acid (13-HpODE). The latter is further reduced into its hydroxyl derivative 13-HODE by GPx in animals, and inhibits blood platelet adhesion to vascular endothelium [69]. Also, several reports have mentioned the oxygenation of LA by COX-2 into 9-HODE [70,71]. 9-HODE might also derive from non-enzymatic peroxidation of LA; then it would be a mixture of 9(R)- and 9(S)-HODE [72].

The indispensable PUFA for the n-3 or omega-3 family is alpha-linolenic acid (ALA or $18: 3 n-3)$. Its required intake in mammals is lower than that $18: 2 n-6$, it is more and more recommended because of the potential benefits of n-3 PUFA to prevent several pathophysiological situations, both by itself and through its conversion into long-chain n-3 PUFA, although such a conversion is assumed to be low. However, 18:3n-3 hardly accumulates in tissues, suggesting that it is actively converted and/or degraded by betaoxidation [73]. In addition to be desaturated and elongated into long-chain n-3 PUFA [74], it may be oxygenated through the 15-/n-6-LOX to make the end-product 13-hydroxy derivative, 13-HOTE, and even some 10,16-dihydroxy derivatives, of which the trans,cis,trans/E,Z,E conjugated trienes have blood platelet anti-aggregatory activity through inhibition of cyclooxygenase [75]. 
These two indispensable PUFA are known for years to compete each other for their conversion into long-chain PUFA derivatives. Nothing is known about a possible competition during their lipoxygenation, then a fluxolipidomics approach would certainly unravel pertinent structures and production kinetics for the oxygenated products. One important analytical issue, that is valid for all lipoxygenase products of PUFA, relates to the stereochemistry of the secondary alcohols in the end-products. It is generally assumed that lipoxygenases, as well as cyclooxygenases, provide (S) products whereas the autoxidation of PUFA yield racemic products in approximately equal amounts of $(\mathrm{R})$ and $(\mathrm{S})$ products. It is expected that the rate of autoxidation products is slower than that for the enzyme-derived products. In addition, the aborted oxygenation of 18:2n-6 and 18:3n-3, for instance, by aspirin-treated/acetylated COX-2, will preferentially produce $\mathrm{R}$ products (i.e. 13(R)-HODE and 13(R)-HOTE, respectively) [76]. These (R) and (S) stereoisomers have to be distinguished on the basis of their biological activities as well as the kinetics of their production, which again justifies the fluxolipidomics approach, with chiral separation of the stereoisomers in that case.

The 20 carbon PUFA addressed so far are precursors of prostanoids. An exception is Mead acid (20:3n-9). This PUFA is a marker of the n-6 PUFA deficiencies in mammals, mainly linoleic acid (18:2n-6). In these deficiencies, Mead acid is produced from oleic acid (18:1n-9) by successive desaturation and elongation [77]. It may partly replace ArA in membrane phospholipids with the same acyl-chain folding having the first three double bonds at carbons 5, 8, 11 in common. However, 20:3n-9 cannot be converted into prostanoids, because of lack of double bond at carbon 14, but is a good substrate of both 5- and 12LOX [78]. $\mathrm{LTB}_{3}$ and $\mathrm{C}_{3}$ may be produced exactly as do $\mathrm{LTB}_{4}$ and $\mathrm{C}_{4}$ from $\mathrm{ArA}$ [79], but no data on their biological activities are available, nor on the kinetics of their formation. The conversion of 20:3n-9 by platelet 12-LOX has been described, with $\mathrm{PGE}_{2}$ mimetic action of the end-product 12-OH-20:3 on platelet aggregation[80]. The measurement of these LOX products must be taken into consideration as a possible competing process relating to the production of ArA counterparts.

The 22 carbon PUFA are more prominent molecules, especially docosahexaenoic acid (DHA, 22:6n-3) in the cerebrovascular system [81]. For that reason and because of its importance in marine lipids, its oxygenation has been extensively studied. Figs. 2 and 3 also show the main features of DHA oxygenation and actions of the metabolites. DHA is a fairly good substrate of the three classical lipoxygenases, 5-, 12-/omega-9, and 15-/omega-6-LOX. Through 5-LOX, the end-products 4- and 7-OH-22:6 (4- \& 7-HDoHE) have been described [82], but no leukotriene-like molecules have been found. Some PPAR gamma agonist activities have been reported, notably relating to the dehydrogenation product 4-oxo- 
22:6 [83]. Platelet 12-LOX converts DHA into the end-products 11- and 14-OH-22:6 (11- \& 14-HDoHE), with the second one being more prominent [84], and both compounds inhibit thromboxane-induced platelet aggregation. Interestingly, 14-OH-22:6 is significantly more potent than 12-HETE [23]. 15-/omega-6 LOX also converts DHA into the end-product 17OH-22:6 with a possible further conversion into 10(S),17(S)-diOH-4Z,7Z,11E,13Z,15E,19Z22:6 in a double lipoxygenation process [85]. This product has been named protectin DX (PDX) to differentiate it from protectin D1 (PD1, 10(R),17(S)-diOH4Z,7Z,11E,13E,15Z,19Z-22:6) previously described as a potent inhibitor of inflammation [86]. PDX belongs to a family of double lipoxygenase products, called poxytrins, sharing the same E,Z,E conjugated triene, reported to inhibit platelet aggregation and cyclooxygenases activities [34,75]. Since its structural and functional characterization, PDX has been shown to inhibit the replication of the influenza virus $[87,88]$, and to restore the insulin sensitivity in diet-induced obese rodents [89]. The close isomers protectins D1 and DX have to be discriminated by proper analytical tools as they are not produced through the same pathways and have different biological activities. In addition to protectins, DHA has been reported to be doubly oxygenated into a position isomer of PD1 by 12-LOX in macrophages, 7(R),14(S)-diOH-4Z,8E,10E,12Z,16Z,19Z-22:6, called maresin-1, which shares the biological activity of PD1 [90]. A more recent report describes that human macrophages also produce an isomer called maresin-2 (13(R),14(S)-diOH-4Z, 7Z, 9E, 11E, 16Z, 19Z -22:6) that shares the action of maresin-1 [91]. Even more complex tri-hydroxylated derivatives are produced from DHA by the combined action of lipoxygenation, and aborted cyclooxygenation (aspirin-treated COX) as well as Cyp $\mathrm{P}_{450}$ action [92]. They are called resolvins $\mathrm{D}(\mathrm{RvD})$ as they accelerate the resolution of inflammation as do RvE from EPA [93]. Most of those DHA metabolites have been found in human plasma, and were altered by omega-3 and aspirin intakes, as shown by some investigators [94], although others failed to find those metabolites in response to high doses of fish oils [95]. Interestingly enough however, some metabolites were increased in the corresponding serum versus plasma (PDX as an example), suggesting the involvement of cells sensitive to blood clotting such as platelets[94]. These numerous oxygenated products of DHA are obviously generated differently with regard to kinetics and location in the vascular compartment that needs elucidation by a fluxolipidomics approach.

Finally, two other 22 carbon PUFA gained attention, namely 22:5n-3 (DPAn-3), as a prominent PUFA in marine lipids, and 22:5n-6 (DPAn-6) as a marker of n-3/omega-3 PUFA deficiencies. An early report described their oxygenation in platelets [96], but no data were available on their biological activities. More recently DPAn-6 [97] and DPAn3 [98] oxygenation has been described in more details. Whereas DPAn-3 oxygenated products 
mimicked their DHA counterparts in a way [98], the biological activity of DPAn-6 oxygenated metabolites was not clear [99].

\section{Non-enzymatic oxygenation of PUFA}

In addition to the stereochemistry of secondary alcohols derived from the reduction of lipoxygenase products by glutathione peroxidases (see above the previous paragraph), a number of cyclic derivatives have been described from ArA, AdA and DHA, and even from the precursors LA and ALA. The cyclic derivatives, called isoprostanes, neuroprostanes and phytoprostanes, became known as markers of oxidative stress in different compartments [100]. Moreover, there is a trend to consider some of them as bioactive oxygenated products as well [101]. Recent reviews can be usefully looked at for further data[102,103]. However, the kinetics of their production is not known, and because no enzymes are involved in such a production, the different rates might just depend on the number of double bonds in the precursor PUFA. Nevertheless, these molecules must be taken into consideration as well in a fluxolipidomics approach to get a more complete balance sheet of time-dependent oxygenation of PUFA, especially because their release from storage lipids where they are produced by reactive oxygen species might occur at different rates.

\section{Conclusion and perspectives}

The great number of oxygenated PUFA metabolites requires appropriate analytical tools to discriminate them. The different pathways for their release from membrane phospholipids, and subsequent oxygenation by different routes (Fig. 2), as well as their potential competition facing the enzymes demand lipidomics approaches that are now commonly used [104]. However, due to different kinetics in the formation of the primary metabolites, and their catabolism into inactive products and/or active ones with different profiles, those measurements at one time-point and in one compartment do not properly reflect the phenotype of a biological system. A fluxolipidomics approach is then requested. The vascular compartment is particularly relevant for those considerations because of the easy exchange of metabolic intermediates between blood and vascular cells that are differently equipped with the enzymes involved.Fig. 3 points out specific functions of some metabolites especially relevant in the blood vessel compartment.

\section{Acknowledgements}

The authors thank the support of Inserm, Inra and INSA-Lyon.

\section{References}

[1] M.A. Crawford, M. Bloom, C.L. Broadhurst, W.F. Schmidt, S.C.Cunnane, C. Galli, K. Gehbrem eskel, F. Linseisen, J. Lloyd-Smith and J.Parkington, Evidence for the unique function of docosahexaenoic acid during the evolution of the modern hominid brain, Lipids 34, 1999,S39-S47, (Review). 
[2] W.E. Lands, Long-term fat intake and biomarkers, Am. J. Clin. Nutr. 61, 1995, 721S725S, (Review).

[3] S.I. Rapoport, In vivo approaches to quantifying and imaging brain arachidonic and docosahexaenoic acid metabolism, J. Pediatr. 143, 2003, S26-S34, (Review).

[4] E.J. Goetzl, S. and W.L. Smith, Specificity of expression and effects of eicosanoid mediators in normal physiology and human diseases, FASEB J. 9, 1995, 1051-1058, (Review).

[5] H.C. Yang, M. Mosior, C.A. Johnson, Y. Chen and E.A. Dennis, Group-specific assays that distinguish between the four major types of mammalian phospholipase A2, Anal. Biochem. 269, 1999,278-288.

[6] J.D. Clark, L.L. Lin, R.W. Kriz, C.S. Ramesha, L.A. Sultzman,A.Y. Lin, N. Milona and J.L. Kn opf, A novel arachidonic acid-selective cytosolic PLA2 contains a $\mathrm{Ca}(2+)$-dependent translocation domain with homology to PKC and GAP, Cell 65, 1991, 1043-1051.

[7] K.S. Authi, M. Lagarde and NN. Crawford, Diacylglycerol lipase activity in human platelet intracellular and surface membranes. Some kinetic properties and fatty acid specificity, FEBS Lett. 180, 1985,95-101.

[8] A. Cane, M. Breton, K. Koumanov, G. Béréziat and O. Colard,Oxidant-induced arachidonic acid release and impairment of fatty acid acylation in vascular smooth muscle cells, Am. J. Phys. 274, 1998,C1040-C1046.

[9] C.M. Markey, A. Alward, P.E. Weller and L.J. Marnett,Quantitative studies of hydroperoxide reduction by prostaglandin $\mathrm{H}$ synthase. Reducing substrate specificity and the relationship of peroxidase to cyclooxygenase activities, J. Biol. Chem. 262, 1987, 6266-6279.

[10] M. Hamberg, J. Svensson and B. Samuelsson, Thromboxanes: a new group of biologically active compounds derived from prostaglandin endoperoxides, Proc. Natl. Acad. Sci. U. S. A. 72, 1975, 2994-2998.

[11] S.J. Gray and S. Heptinstall, Interactions between prostaglandin E2 and inhibitors of platelet aggregation which act through cyclic AMP, Eur. J. Pharmacol. 194, 1991, 63-70.

[12] D.C. Mills and D.E. Macfarlane, Stimulation of human platelet adenylate cyclase by prostaglandin D2, Thromb. Res. 5, 1975,401-412.

[13] S. Narumiya, Y. Sugimoto and F. Ushikubi, Prostanoid receptors: structures, properties, and functions, Physiol. Rev. 79, 1999,1193-1226, (Review).

[14] M. Amin, Simultaneous determination of prostaglandins (PG) E2, A2 and B2 and stability studies of PGE2 in pharmaceutical preparations by ion-pair reversed phase HPLC, Pharm. ActaHelv. 64, 1989,45-50. 
[15] M. Fukushima, Biological activities and mechanisms of action of PGJ2 and related compounds: an update, Prostaglandins Leukot. Essent. Fat. Acids 47, 1992, 1-12, (Review).

[16] T. Ide, K. Egan, L.C. Bell-Parikh and G.A. FitzGerald, Activation of nuclear receptors by prostaglandins, Thromb. Res. 110, 2003,311-315, (Review).

[17] M. Lagarde, Metabolism of fatty acids by platelets and the functions of various metabolites in mediating platelet function, Prog. Lipid Res. 27, 1988, 135-152, (Review).

[18] K. Watanabe, Prostaglandin F synthase, Prostaglandins Other Lipid Mediat. 68-69, 2002, 401407, (Review).

[19] Y. Kanaoka and Y. Urade, Hematopoietic prostaglandin D synthase,ProstaglandinsLeukot. Essent. Fat. Acids 69, 2003, 163-167, (Review).

[20] S. Hara, D. Kamei, Y. Sasaki, AA. Tanemoto, Y. Nakatani and M.Murakami, Prostaglandin E synthases: understanding their pathophysiological roles through mouse genetic models, Biochimie 92, 2010,651-659.

[21] W.C. Chang, J. Nakao, H. Orimo and S. Murota, Effects of reduced glutathione on the 12lipoxygenase pathways in rat platelets, Biochem. J. 202, 1982, 771-776.

[22] C. Calzada, E. Véricel, B. Mitel, L. Coulon and M. Lagarde, 12(S)-

Hydroperoxyeicosatetraenoic acid increases arachidonic acid availability in collagen-primed platelets, J. Lipid Res. 4, 2001, 1467-1473.

[23] M. Croset, A. Sala, G. Folco and M. Lagarde, Inhibition by lipoxygenase products of TXA2like responses of platelets and vascular smooth muscle. 14-Hydroxy from 22:6n-3 is more potent than 12-HETE,Biochem. Pharmacol. 37, 1988, 1275-1280.

[24] P. Fonlupt, M. Croset and M. Lagarde, 12-HETE inhibits the binding of PGH2/TXA2 receptor ligands in human platelets, Thromb. Res. 63, 1991, 239-248.

[25] J. Nowak and G.A. FitzGerald, Redirection of prostaglandin endoperoxide metabolism at the platelet-vascular interface in man, J. Clin. Invest. 83, 1989, 380-385.

[26] F. Merhi-

Soussi, Z. Dominguez, O. Macovschi, M. Dubois, G. Nemoz,M. Lagarde and A.F. Prigent, M echanisms involved in the stimulation of prostacyclin synthesis by human lymphocytes in human umbilical vein endothelial cells, Br. J. Pharmacol. 139, 2003, 321-328.

[27] S.L. Hong, T. Carty and D. Deykin, Tranylcypromine and 15-hydroperoxyarachidonate affect arachidonic acid release in addition to inhibition of prostacyclin synthesis in calf aortic endothelial cells, J. Biol. Chem. 255, 1980, 9538-9540. 
[28] W. Lands, R. Lee and W. Smith, Factors regulating the biosynthesis of various prostaglandins, Ann. N. Y. Acad. Sci. 180, 1971, 107-122.

[29] B. Samuelsson, Leukotrienes: mediators of allergic reactions and inflammation, Int. Arch. Allergy Appl. Immunol. 66 (Suppl. 1), 1981,98-106, (Review).

[30] O. Rådmark, C. Malmsten, B. Samuelsson, D.A. Clark, G. Goto, A.Marfat and E.J. Corey, Leu kotriene A: stereochemistry and enzymatic conversion to leukotriene B4, Biochem. Biophys. Res. Commun. 92, 1980, 954-961.

[31] A.W. Ford-Hutchinson, A. Rackham, R. Zamboni, J. Rokach and S.Roy, Comparative biological activities of synthetic leukotriene B4 and its omega-oxidation products, Prostaglandins 25, 1983, 29-37.

[32] P. Borgeat, B. FruteaudeLaclos, S. Picard, J. Drapeau, P. Vallerandand E.J. Corey, Studies on the mechanism of formation of the 5S, 12S-dihydroxy-6,8,10,14(E,Z,E,Z)-icosatetraenoic acid in leukocytes, Prostaglandins 23, 1982, 713-724.

[33] M. Croset and M. Lagarde, Stereospecific inhibition of PGH2-induced platelet aggregation by lipoxygenase products of icosaenoic acids, Biochem. Biophys. Res. Commun. 112, 1983,878883.

[34] P. Chen, E. Véricel, M. Lagarde and M. Guichardant, Poxytrins, a class of oxygenated products from polyunsaturated fatty acids, potently inhibit blood platelet aggregation, FASEB J. 25, 2011, 382-388.

[35] W.S. Powell, M. Hashefi, J.R. Falck, K. Chauhan, J. Rokach, S.S.Wang, E. Mills and R.J. Mac Leod, Effects of oxo and dihydro metabolites of 12-hydroxy-5,8,10,14-eicosatetraenoic acid on chemotaxis and cytosolic calcium levels in human neutrophils, J. Leukoc. Biol. 57, 1995, 257-263.

[36] W.S. Powell and J. Rokach, The eosinophil chemoattractant 5-oxo-ETE and the OXE receptor, Prog. Lipid Res. 52, 2013, 651-665.

[37] O. Rådmark, C. Malmsten and B. Samuelsson, Leukotriene A4: enzymatic conversion to leukotriene C4, Biochem. Biophys. Res. Commun. 96, 1980, 1679-1687.-

[38] B. Samuelsson, S.E. Dahlén, J.A. Lindgren, C.A. Rouzer and C.N.Serhan, Leukotrienes and lipoxins: structures, biosynthesis, and biological effects, Science 237, 1987, 11711176, (Review).

[39] R.C. Murphy and M.A. Gijón, Biosynthesis and metabolism of leukotrienes, Biochem. J. 405, 2007, 379-395, (Review). 
[40] H.S. Hansen, 15-Hydroxyprostaglandin review,Prostaglandins 12, 1976, 647-679.

[41] S.E. Barrow, J. Cockcroft, C.T. Dollery, N.E. Hickling and J.M.Ritter, Identification of 13,14dihydro-15-oxo-prostaglandin F2 alpha in the circulation during infusions of bradykinin and prostaglandin E2 in man, Br. J. Pharmacol. 91, 1987, 245-250.

[42] U. Diczfalusy and S.E. Alexson, Identification of metabolites from peroxisomal beta-oxidation of prostaglandins, J. Lipid Res. 31, 1990, 307-314.

[43] U. Diczfalusy, Beta-oxidation of eicosanoids, Prog. Lipid Res. 33, 1994, 403-428, (Review).

[44] T.L. Kaduce, X. Fang, S.D. Harmon, C.L. Oltman, K.C.Dellsperger, L.M. Teesch, V.R. Gopal, J.R. Falck, W.B.Campbell, N.L. Weintraub and A.A. Spector, 20-Hydroxyeicosatetraenoic acid (20-HETE) metabolism in coronary endothelial cells, J. Biol. Chem. 279, 2004, 26482656.

[45] J.H. Capdevila, J.R. Falck and R.W. Estabrook, Cytochrome P450 and the arachidonate cascade, FASEB J. 6, 1992,731-736, (Review).

[46] E.H. Oliw, Oxygenation of polyunsaturated fatty acids by cytochrome P450 monooxygenases, Prog. Lipid Res. 33, 1994,329-354, (Review).

[47] J.D. Imig, Epoxides and soluble epoxide hydrolase in cardiovascular physiology, Physiol. Rev. 92, 2012, 101-130.

[48] D.F. Horrobin, Interactions between n-3 and n-6 essential fatty acids (EFAs) in the regulation of cardiovascular disorders and inflammation,Prostaglandins Leukot. Essent. Fat. Acids 44, 1991, 127-131, (Review).

[49] M. Lagarde, A. Gharib and M. Dechavanne, Different utilization of arachidonic and dihomogammalinolenic acids by human platelet prostaglandin synthetase, Biochimie 59, 1977, 935-937.

[50] P. Needleman, M.O. Whitaker, A. Wyche, K. Watters, H. Sprecherand A. Raz, Manipulation of platelet aggregation by prostaglandins and their fatty acid precursors: pharmacological basis for a therapeutic approach, Prostaglandins 19, 1980, 165-181.

[51] S.M. Wolfe and N.R. Shulman, Inhibition of platelet energy production and release reaction by PGE1, theophylline and cAMP, Biochem. Biophys. Res. Commun. 41, 1970, 128-134.

[52] P. Needleman, M. Minkes and A. Raz, Thromboxanes: selective biosynthesis and distinct biological properties, Science 193, 1976, 163-165.

[53] S. Fischer and P.C. Weber, Prostaglandin I3 is formed in vivo in man after dietary eicosapentaenoic acid, Nature 307, 1984, 165-168. 
[54] M.O. Whitaker, A. Wyche, F. Fitzpatrick, H. Sprecher and P.Needleman, Triene prostaglandins: prostaglandin D3 and icosapentaenoic acid as potential antithrombotic substances, Proc. Natl. Acad. Sci. U. S. A. 76, 1979, 5919-5923.

[55] S.P. Tull, C.M. Yates, B.H. Maskrey, V.B. O'Donnell, J.Madden, R.F. Grimble, P.C. Calder, G. B. Nash and G.E. Rainger,Omega-3 Ffatty acids and inflammation: novel interactions reveal a new step in neutrophil recruitment, PLoS Biol. 7, 2009, e1000177.

[56] J. LefilsLacourtablaise, M. Socorro, A. Géloën, P. Daira, C. Debard,E. Loizon, M. Guichardant , Z. Dominguez, H. Vidal, M. Lagarde andN. Bernoud-Hubac, The eicosapentaenoic acid metabolite 15 -deoxy- $\delta(12,14)$-prostaglandin $\mathrm{J} 3$ increases adiponectin secretion by adipocytes partly via a PPAR $\gamma$-dependent mechanism, PLoS One 8, 2013, e63997.

[57] D. Bagga, L. Wang, R. Farias-Eisner, J.A. Glaspy and S.T. Reddy,Differential effects of prostaglandin derived from omega- 6 and omega-3 polyunsaturated fatty acids on COX-2 expression and IL-6 secretion, Proc. Natl. Acad. Sci. U. S. A. 100, 2003, 1751-1756.

[58] M. VanRollins, L. Horrocks and H. Sprecher, Metabolism of 7,10,13,16-docosatetraenoic acid to dihomo-thromboxane, 14-hydroxy-7,10,12-nonadecatrienoic acid and hydroxy fatty acids by human platelets, Biochim. Biophys. Acta 833, 1985, 272-280.

[59] R. Harkewicz, E. Fahy, A. Andreyev and E.A. Dennis, Arachidonate-derived dihomoprostaglandin production observed in endotoxin-stimulated macrophage-like cells, J. Biol. Chem. 282, 2007, 2899-2910.

[60] W.B. Campbell, J.R. Falck, J.R. Okita, A.R. Johnson and K.S.Callahan, Synthesis of dihomoprostaglandins from adrenic acid (7,10,13,16-docosatetraenoic acid) by human endothelial cells, Biochim. Biophys. Acta 837, 1985, 67-76.

[61] H. Sprecher and M.M. Careaga, Metabolism of (n-6) and (n-3) polyunsaturated fatty acids by human platelets, Prostaglandins Leukot. Med. 23, 1986, 129-134.

[62] A.G. Leitch, T.H. Lee, E.W. Ringel, J.D. Prickett, D.R.Robinson, S.G. Pyne, E.J. Corey, J.M. Drazen, K.F. Austen andR.A. Lewis, Immunologically induced generation of tetraene and pentaene leukotrienes in the peritoneal cavities of menhaden-fed rats, $J$. Immunol. 132, 1984, 2559-2565.

[63] T.H. Lee, J.M. Mencia-

Huerta, C. Shih, E.J. Corey, R.A. Lewisand K.F. Austen, Characterization and biologic properties of 5,12-dihydroxy derivatives of eicosapentaenoic acid, including leukotriene B5 and the double lipoxygenase product, J. Biol. Chem. 259, 1984, 2383-2389. 
[64] J.L. Wallace and G.W. McKnight, Comparison of the damage-promoting effects of leukotrienes derived from eicosapentaenoic acid and arachidonic acid on the rat stomach, $J$. Exp. Med. 171, 1990, 1827-1832.

[65] M. VanRollins, Synthesis and characterization of cytochrome P-450 epoxygenase metabolites of eicosapentaenoic acid, Lipids 25, 1990,481-490.

[66] C.N. Serhan, S. Hong, K. Gronert, S.P. Colgan, P.R. Devchand,G. Mirick and R.L. Moussignac , Resolvins: a family of bioactive products of omega-3 fatty acid transformation circuits initiated by aspirin treatment that counter proinflammation signals, J. Exp. Med. 196, 2002,1025-1037.

[67] S.F. Oh, T.W. Vickery and C.N. Serhan, Chiral lipidomics of E-series resolvins: aspirin and the biosynthesis of novel mediators, Biochim. Biophys. Acta 2011, 1811, 737-747.

[68] M. Hamberg, Steric analysis of hydroperoxides formed by lipoxygenase oxygenation of linoleic acid, Anal. Biochem. 43, 1971,515-526, (See comment in PubMed Commons below).

[69] M.R. Buchanan, T.A. Haas, M. Lagarde and M. Guichardant, 13-Hydroxyoctadecadienoic acid is the vessel wall chemorepellant factor, LOX,J. Biol. Chem. 260, 1985, 16056-16059, (See comment in PubMed Commons below).

[70] M. Hamberg and B. Samuelsson, Stereochemistry in the formation of 9-hydroxy-10,12octadecadienoic acid and 13-hydroxy-9,11-octadecadienoic acid from linoleic acid by fatty acid cyclooxygenase, Biochim. Biophys. Acta 617, 1980, 545-547.

[71] T.L. Kaduce, P.H. Figard, R. Leifur and A.A. Spector, Formation of 9-hydroxyoctadecadienoic acid from linoleic acid in endothelial cells, J. Biol. Chem. 264, 1989, 6823-6830.

[72] Q.H. Lê, M. ElAlaoui, E. Véricel, B. Ségrestin, L. Soulère, M.Guichardant, M. Lagarde, P. Mo ulin and C. Calzada, Glycoxidized HDL, HDL enrichedwithoxidizedphospholipids and HDL fromdiabetic patients inhibitplateletfunction, J. Clin. Endocrinol. Metab. 100, 2015, 20062014.

[73] S.C. Cunnane, New developments in alpha-linolenate metabolism with emphasis on the importance of beta-oxidation and carbon recycling, World Rev. Nutr. Diet. 88, 2001, 178183, (Review).

[74] G. Burdge, Alpha-linolenic acid metabolism in men and women: nutritional and biological implications, Curr. Opin. Clin. Nutr. Metab. Care 7, 2004,137-144, (Review).

[75] M. Liu, PP. Chen, E. Véricel, M. Lelli, L. Béguin, M. Lagarde andM. Guichardant, Characteriz ation and biological effects of di-hydroxylated compounds deriving from the lipoxygenation of ALA, J. Lipid Res. 54, 2013, 2083-2094. 
[76] C. Schneider and A.R. Brash, Stereospecificity of hydrogen abstraction in the conversion of arachidonic acid to 15R-HETE by aspirin-treated cyclooxygenase-2. Implications for the alignment of substrate in the active site, J. Biol. Chem. 275, 2000, 4743-4746.-

[77] W.O. Lundberg, The significance of cis, cis, cis 5,8,11 eicosatrienoic acid in essential fatty acid deficiency, Nutr. Rev. 38, 1980, 233-235.

[78] B.A. Jakschik, A.R. Morrison and H. Sprecher, Products derived from 5,8,11-eicosatrienoic acid by the 5-lipoxygenaseleukotriene pathway,J. Biol. Chem. 258, 1983, 12797-12800.

[79] S. Hammarström, Conversion of 5,8,11-eicosatrienoic acid to leukotrienes C3 and D3, J. Biol. Chem. 256, 1981, 2275-2279.

[80] M. Lagarde, M. Burtin, M. Rigaud, H. Sprecher, M. Dechavanne and S. Renaud, Prostaglandin E2-like activity of 20:3n-9 platelet lipoxygenase end-product, FEBS Lett. 181, 1985, 53-56.

[81] N. Salem, Jr., B. Litman, H.Y. Kim and K. Gawrisch, Mechanisms of action of docosahexaenoic acid in the nervous system, Lipids 36, 2001,945-959, (Review).

[82] T.H. Lee, J.M. Drazen, R.A. Lewis and K.F. Austen, Substrate and regulatory functions of eicosapentaenoic and docosahexaenoic acids for the 5-lipoxygenase pathway. Implications for pulmonary responses, Prog. Biochem. Pharmacol. 20, 1985, 1-17, (Review).

[83] P. Sapieha, A. Stahl, J. Chen, M.R. Seaward, K.L. Willett, N.M.Krah, R.J. Dennison, KMK.M. Connor, C.M. Aderman, E. Liclican,A. Carughi, D. Perelman, Y. Kanaoka, J.P. Sangiovanni, K. Gronertand L.E. Smith, 5-Lipoxygenase metabolite 4-HDHA is a mediator of the antiangiogenic effect of $\omega-3$ polyunsaturated fatty acids, Sci. Transl. Med. 3, 2011, 69ra12.

[84] M.I. Aveldaño and H. Sprecher, Synthesis of hydroxy fatty acids from 4, 7, 10, 13, 16, 19-[114C] docosahexaenoic acid by human platelets, J. Biol. Chem. 258, 1983, 9339-9343.

[85] P. Chen, B. Fenet, S. Michaud, N. Tomczyk, E. Véricel, M. Lagardeand M. Guichardant, Full characterization of PDX, a neuroprotectin/protectin D1 isomer, which inhibits blood platelet aggregation, FEBS Lett. 589, 2009, 3478-3484.

[86] C.N. Serhan and N. Chiang, Endogenous pro-resolving and anti-inflammatory lipid mediators: a new pharmacologic genus, Br. J. Pharmacol. 153, 2008, S200-S215, Review.

[87] M. Morita, K. Kuba, A. Ichikawa, M. Nakayama, J. Katahira, R.Iwamoto, T. Watanebe, S. Sak abe, T. Daidoji, S. Nakamura, A.Kadowaki, T. Ohto, H. Nakanishi, R. Taguchi, T. Nakaya, M .Murakami, Y. Yoneda, H. Arai, Y. Kawaoka, J.M. Penninger, M.Arita and Y. Imai, The lipid mediator protectin D1 inhibits influenza virus replication and improves severe influenza, Cell 153, 2013, 112-125. 
[88] Y. Imai, Role of omega-3 PUFA-derived mediators the protectins in influenza virus infection, Biochim. Biophys. Acta 2015, 1851, 496-502.

[89] P.J. White, P. St-Pierre, A. Charbonneau, P.L. Mitchell, E. St-

Amand, B. Marcotte and A. Marette, Protectin DX alleviates insulin resistance by activating a myokine-liver glucoregulatory axis,Nat. Med. 20, 2014, 664-669.

[90] C.N. Serhan, R. Yang, K. Martinod, K. Kasuga, P.S. Pillai, T.F.Porter, S.F. Oh and M. Spite,

Maresins: novel macrophage mediators with potent antiinflammatory and proresolving actions, $J$. Exp. Med. 206, 2009, 15-23.

[91] B. Deng, C.W. Wang, H.H. Arnardottir, Y. Li, C.Y. Cheng, J.Dalli and C.N. Serhan, Maresin biosynthesis and identification of maresin 2, a new anti-inflammatory and pro-resolving mediator from human macrophages, PLoS One 2014, e102362.

[92] M. Arita, C.B. Clish and C.N. Serhan, The contributions of aspirin and microbial oxygenase to the biosynthesis of anti-inflammatory resolvins: novel oxygenase products from omega-3 polyunsaturated fatty acids,Biochem. Biophys. Res. Commun. 338, 2005, 149-157, (Review).

[93] R.R. Ji, Z.Z. Xu, G. Strichartz and C.N. Serhan, Emerging roles of resolvins in the resolution of inflammation and pain, Trends Neurosci. 34, 2011, 599-609, (Review).

[94] R.A. Colas, M. Shinohara, J. Dalli, N. Chiang and C.N. Serhan,Identification and signature profiles for pro-resolving and inflammatory lipid mediators in human tissue, Am. J. Physiol. Cell Physiol. 307, 2014,C39-C54.

[95] C. Skarke, N. Alamuddin, J.A. Lawson, J.F. Ferguson, M.P.Reilly and G.A.FitzGerald, Bioacti ve products formed in humans from fish oils, J. Lipid Res. Jul 152015.

[96] M. Guichardant and M. Lagarde, Studies on platelet lipoxygenase specificity towards icosapolyenoic and docosapolyenoic acids, Biochim. Biophys. Acta 836, 1985, 210-214.

[97] B. Dangi, M. Obeng, J.M. Nauroth, M. Teymourlouei, M.Needham, K. Raman and L.M. Arterb urn, Biogenic synthesis, purification, and chemical characterization of anti-inflammatory resolvins derived from docosapentaenoic acid (DPAn-6), J. Biol. Chem. 284, 2009,1474414759.

[98] J. Dalli, R.A. Colas and C.N. Serhan, Novel n-3 immunoresolvents: structures and actions, Sci. Rep. 3, 2013, 1940.

[99] B. Dangi, M. Obeng, J.M. Nauroth, G. Chung, E. BaileyHall, T.Hallenbeck and L.M. Arterburn , Metabolism and biological production of resolvins derived from docosapentaenoic acid (DPAn-6), Biochem. Pharmacol. 79, 2010, 251-260. 
[100] L.J. Roberts, II and J.P. Fessel, The biochemistry of the isoprostane, neuroprostane, and isofuranpathways of lipid peroxidation, Chem. Phys. Lipids 128, 2004, 173-186.

[101] J. Roy, J.Y. LeGuennec, J.M. Galano, J. Thireau, V. BultelPoncé,M. Demion, C. Oger,J.C.Lee and T. Durand, Non-enzymatic cyclic oxygenated metabolites of omega-3 polyunsaturated fatty acid: bioactive drugs?, Biochimie Jun 232015.

[102] G.L. Milne, Q. Dai and L.J. Roberts, II, The isoprostanes-25-years later,Biochim. Biophys. Acta 2015, 1851, 433-445.

[103] J.M. Galano, J.C. Lee, C. Gladine, B. Comte, J.Y. LeGuennec,C. Oger and T. Durand, Nonenzymatic cyclic oxygenated metabolites of adrenic, docosahexaenoic, eicosapentaenoic and $\alpha$-linolenic acids; bioactivities and potential use as biomarkers, Biochim. Biophys. Acta 2015, 1851, 446-455.

[104] G. Astarita, A.C. Kendall, E.A. Dennis and A. Nicolaou, Targeted lipidomic strategies for oxygenated metabolites of polyunsaturated fatty acids, Biochim. Biophys. Acta 2015, 1851, 456-468.

[105] A. Voss, M. Reinhart, S. Sankarappa and H. Sprecher, The metabolism of 7,10,13,16,19docosapentaenoic acid to 4,7,10,13,16,19-docosahexaenoic acid in rat liver is independent of a 4-desaturase, J. Biol. Chem. 266, 1991, 19995-20000 